\title{
Equity and Efficiency in Rationed Labor Markets
}

Max Planck Institute for Tax Law and Public Finance

Working Paper 2016 - 04

March 2016

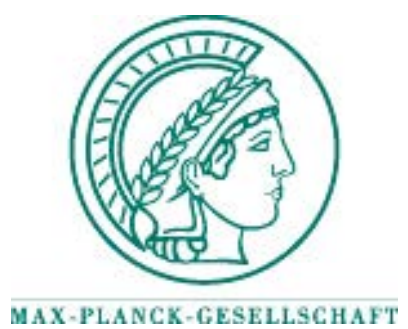

Max Planck Institute for

Tax Law and Public Finance

Department of Business and Tax Law

Department of Public Economics

http:/ / www.tax.mpg.de 
Working papers of the Max Planck Institute for Tax Law and Public Finance Research Paper Series serve to disseminate the research results of work in progress prior to publication to encourage the exchange of ideas and academic debate. Inclusion of a paper in the Research Paper Series does not constitute publication and should not limit publication in any other venue. The preprints published by the Max Planck Institute for Tax Law and Public Finance represent the views of the respective author(s) and not of the Institute as a whole. Copyright remains with the author(s).

Max Planck Institute for Tax Law and Public Finance

Marstallplatz 1

D-80539 Munich

Tel: $\quad+498924246-0$

Fax: $\quad+498924246-501$

E-mail: ssrn@tax.mpg.de

http://www.tax.mpg.de 


\title{
Equity and efficiency in rationed labor markets
}

\author{
Aart Gerritsen*
}

\author{
March 2016
}

The social welfare implications of income tax policy are shown to critically depend on whether or not labor markets are rationed i.e., on the existence of involuntary unemployment. With rationed labor markets, raising taxes on the employed and transfers towards the unemployed might improve both equity and efficiency. It improves equity by redistributing income from the employed to the unemployed; it improves efficiency as it encourages people with a small utility surplus of employment to exit the labor market, leaving their jobs for people with a higher utility surplus. I derive conditions under which this result continues to hold when only part of the labor market is rationed. I also show that conventional tax incidence results break down in rationed labor markets.

JEL codes: H21; J21; E24

Keywords: Involuntary unemployment, inefficient rationing, optimal taxation

\footnotetext{
* Max Planck Institute for Tax Law and Public Finance, Department of Public Economics, Marstallplatz 1, 80539 Munich, Germany. Tel.: +49-89-24246-5256; Fax: +4989-24246-5299; E-mail: aart.gerritsen@tax.mpg.de; Internet: https://sites.google. com/site/aartgerritsen/. I thank Robin Boadway, Kai Brückerhoff, Bas Jacobs, Kai Konrad, Jenny Ligthart, Frederick van der Ploeg, Marit Rehavi, Hendrik Vrijburg, Floris Zoutman, and participants of numerous seminars and conferences for helpful comments and discussions. Financial support from The Netherlands Organization for Scientific Research (NWO Vidi Grant No. 452-07-013) is gratefully acknowledged.
} 


\section{Introduction}

It is well-understood that labor market policies and institutions that fix wage rates above their market-clearing level lead to an inefficient allocation of production factors. More people would like to work at prevailing wages than there are jobs, causing involuntary unemployment. What is less understood is that such labor rationing entails two different types of inefficiency. First, there are potential labor-market transactions between firms and the unemployed that carry a positive surplus for both, but are nevertheless not executed due to inflexible wages. Second, in the absence of a secondary market for jobs, there is no market mechanism which ensures that the limited amount of jobs is allocated to the individuals with the highest utility surplus of work. That is, there is no reason for the market to discriminate between two individuals with identical productivity but different levels of participation costs or, similarly, different levels of reservation wages. In stark contrast to the first, this second source of rationing inefficiency has received little attention within the economics literature.

If a limited amount of jobs is inefficiently allocated among the individuals that would like to work, public policy that affects the degree of rationing - obviously minimum-wage legislation, but also participation policy and taxation - requires reappraisal. This paper is an attempt towards such reappraisal and provides a theoretical analysis of the consequences of inefficient labor rationing for optimal tax policy. I show that, in the presence of inefficient rationing, government might find it optimal to increase the relative rewards of being voluntarily unemployed by increasing unemployment benefits, financed by higher taxes on labor income. In response, workers that derive least utility from their job decide to stop working and reap the increased benefits of being unemployed. In a clearing labor market, such decision entails an efficiency loss as aggregate employment, and thus the tax base, decline. In rationed labor markets, however, there is no such efficiency cost because aggregate employment does not fall. The reason for this is that there were more potential workers than jobs in the first place.

Instead, creating tax incentives for people to stop working yields an efficiency gain: by giving up their job, individuals who derive relatively little utility from their work create jobs for unemployed people who derive 
more utility from working. Government can thus correct for the absence of a free exchange of jobs between the employed and the unemployed by appropriately setting taxes and transfers. Moreover, since the proposed tax reform entails transfers from the employed towards the unemployed, it improves equity as well as efficiency. This implies that the traditional trade-off between equity and efficiency does not exist within a context of rationed labor markets. The optimality of raising both taxes on labor and benefits for the unemployed is therefore robust under redistributive social preferences. As a corollary, it is suboptimal to increase the degree of rationing by implementing a binding minimum wage or by stimulating participation in rationed labor markets.

I formally derive these results for a simple economy with a single type of rationed labor, and subsequently determine to what extent the policy implications carry over to a richer context with a mix of rationed and clearing labor markets, different types of tax instruments, and an endogenous wage floor.

First, results do not necessarily carry over to a richer general equilibrium framework with both skilled and unskilled labor as factors of production. I consider the intuitive case in which the unskilled segment of the labor market is rationed, while the skilled segment clears. Increasing unskilled taxes and unemployment benefits so as to reduce the inefficiency of rationing now also affects skill decisions. I show that the policy reform improves both equity and efficiency if it leads to more skilled labor supply. It improves equity by transferring resources from the employed to the unemployed, whereas it improves efficiency because it reduces the inefficient ration and because the resulting increase in skilled labor supply expands the tax base.

However, the policy reform's effect on skilled labor supply is theoretically ambiguous. While the increased tax burden on unskilled workers incentivizes individuals to supply skilled rather than unskilled labor, the resulting decline in rationing makes unskilled labor supply relatively more attractive. The net effect crucially depends on the relevance of rationing for individuals who are relatively indifferent between supplying skilled and unskilled labor - which in turn depends on how the limited amount of unskilled jobs is allocated among the individuals who would like to work. Since we know very little about the allocation of rationed jobs, I stress the 
importance of improving our empirical understanding of how changes in unskilled unemployment affect individuals' skill decisions.

Second, while the main results are derived for an increase in the employee part of the income tax, I show that the same results do not apply for an increase in the employer part of the income tax. The latter would result in even lower demand for - rather than lower supply of - rationed labor, and therefore worsen rationing and its inefficiencies. Thus, the conventional incidence equivalence of employees' and employers' taxes does not hold within a context of rationed labor markets. Third, I consider the case in which the wage floor is endogenously determined by a trade union. As long as government raises taxes in response to involuntary unemployment, this effectively incentivizes unions to moderate their wage demands - leading to reduced rationing. The conclusion that labor income taxes should respond positively to involuntary unemployment thus carries over to the case of an endogenously set wage floor.

This paper is related to a small strand of the literature that considers optimal taxation in the presence of involuntary unemployment. These studies consider different sources of unemployment, ranging from minimum wages (e.g., Allen, 1987; Guesnerie and Roberts, 1987; Marceau and Boadway, 1994; Boadway and Cuff, 2001; Lee and Saez, 2012; Gerritsen and Jacobs, 2015), to union-set wages (e.g., Sørensen, 1999; Aronsson and Sjögren, 2004; Hummel and Jacobs, 2016), to downward rigid wage floors (e.g., Landais, Michaillat, and Saez, 2013; Kroft et al., 2015). Most of these studies consider identical agents so that the efficiency of labor rationing plays no role of significance. Others impose very specific assumptions on how the limited amount of jobs is allocated among job seekers. For example, Marceau and Boadway (1994) and Lee and Saez (2012) both find a potential role for labor rationing even in the presence of optimal taxes. But the results of both studies are importantly driven by the assumption that involuntary unemployment is concentrated on those who are indifferent between unskilled employment and their outside option (be it voluntary unemployment or skilled employment). I contribute to these studies by explicitly taking into account the possibly inefficient allocation of scarce jobs.

Theoretically, in the absence of a secondary market, there is little reason to assume that rationed goods are acquired by those individuals who 
desire them most (Tobin, 1952; Bulow and Klemperer, 2012). And indeed, empirical evidence on the inefficient allocation of rationed commodities is abundant. As noted by Luttmer (2007), such inefficiencies have been reported for the U.S. residential market for gas (Davis and Kilian, 2011), the gasoline market (Deacon and Sonstelie, 1989; Frech and Lee, 1987) and for the housing rental market (Glaeser and Luttmer, 2003). Lott (1990), within the context of a binding minimum wage, was the first to argue that rationed jobs might also be allocated inefficiently. This argument has recently been repeated by Palda (2000), Luttmer (2007), and Gerritsen and Jacobs (2015). Unfortunately, the empirical literature provides little guidance when it comes to the efficiency of job allocation. The only empirical evidence on the efficiency of labor rationing is provided by Luttmer (2007). He estimates the effects of the minimum wage on various proxies for inefficient rationing among lowly skilled workers, but finds mixed results depending on which skill classification is used. ${ }^{1}$

Finally, and more broadly, this study relates to the discussion on whether individual elasticities of taxable income are sufficient statistics for the measurement of the marginal dead-weight loss of taxation (e.g., Chetty, 2009; Saez, Slemrod, and Giertz, 2012; Feldstein, 1999). Previous studies have shown that elasticities might overstate the marginal dead-weight loss of taxation because of positive externalities associated with tax avoidance and evasion. I show that individual reductions in labor supply might even lead to a decline in the total dead-weight loss when the labor market is rationed.

In Section 2, I consider a simple model of labor rationing to illustrate the main narrative of the paper. In Section 3, I consider a more elaborate model with two segments of the labor market: a rationed unskilled segment and a clearing skilled segment. In Section 4, I discuss the difference in incidence of employee and employer taxes, as well as an endogenous union-set wage floor. I conclude with a discussion of the results.

\footnotetext{
${ }^{1}$ This is in stark contrast to the first source of inefficiency, represented by the aggregate employment effects of above-market-clearing wage rates. Even though there is little consensus on the disemployment effects of minimum wages, many empirical studies have attempted to estimate this effect - see Neumark and Wascher (2006) and Schmitt (2013) for surveys. For a recent meta-study on the available empirical evidence on labor demand elasticities, see Lichter, Peichl, and Siegloch (2015).
} 


\section{Rationing and its policy implications}

\subsection{A simple model of labor rationing}

In this section I present a highly stylized model of a rationed labor market to demonstrate the basic narrative of the paper. Individuals in this economy constitute a continuum $\mathcal{I}$ with mass $n=1$. They decide to notionally supply labor in a rationed labor market or be voluntarily unemployed. To keep things as simple as possible, I assume that rationing originates from a combination of a rigid wage floor and a technology featuring decreasing returns to labor. This yields a fixed mass of available jobs, denoted $\bar{m}$. I assume that there are more individuals then jobs: $\bar{m}<n=1$. Since there are more potential workers than jobs, not every individual will obtain a job. Ultimately, there will be a share $n_{L}=\bar{m}$ employed individuals and a share $n_{U}=1-\bar{m}$ unemployed individuals (be it voluntarily or involuntarily), such that $n_{L}+n_{U}=n=1$.

Individuals are heterogeneous with respect to their costs of work, $c$, which has a cumulative distribution function $H(c)$, with density $h(c) \equiv$ $H^{\prime}(c)$, and support $[0, \bar{c}]$. It can be seen as a combination of monetary costs associated with work (e.g. travel costs, costs of education, child care) and loss of leisure. An individual, if employed, inelastically supplies one unit of labor. He then earns after-tax income $w_{L}-t_{L}$, with $w_{L}$ the wage floor and $t_{L}$ a tax on labor; and he suffers costs of work. If unemployed, he does not suffer any work-related costs and earns unemployment benefits $-t_{U}$. Government is assumed to be unable to distinguish between the voluntary unemployed and the involuntary unemployed, such that there is no distinction in transfers for the two different types of unemployment. ${ }^{2}$ Finally, I assume that utility is linear in consumption and costs of work. ${ }^{3}$ Consequently, the utility functions of individual $i \in \mathcal{I}$ when employed and

\footnotetext{
${ }^{2}$ In reality, government might be able to imperfectly distinguish between the two types of unemployment. It is straightforward to expand the model with differentiated transfers to the involuntary and the voluntary unemployed. While this would add more notation, it would not affect any of the results.

${ }^{3}$ As explained below, the policy implications drawn in this section hold a fortiori for any concave transformation of the utility functions.
} 
when unemployed are given by:

$$
\begin{aligned}
V_{L}^{i} & \equiv w_{L}-t_{L}-c^{i}, \\
V_{U}^{i} & \equiv-t_{U},
\end{aligned}
$$

where $c^{i}$ denotes individual $i$ 's costs of work.

An individual notionally supplies labor if $V_{L}^{i}>V_{U}^{i}$. Hence, there is a critical level of the costs of work that leaves an individual indifferent between employment and unemployment. This critical level, denoted $c^{*}$, is determined by $V_{L}^{i}=V_{U}^{i}$ :

$$
c^{*}=w_{L}-t_{L}+t_{U} .
$$

Every individual with costs of work above $c^{*}$ prefers to be unemployed; every individual with lower costs of work prefers to be employed. A rationed labor market implies that the number of individuals that would like to work exceeds the number of jobs, such that $H\left(c^{*}\right)>\bar{m}$. This requires the adoption of a rationing schedule that describes which of the individuals that would like to work obtain a job and which do not. For this, I assume that chances of unemployment might differ among individuals with different costs of work. I let $u_{c}$ denote the probability of unemployment for individuals with costs of work $c$. Naturally, these unemployment probabilities should add up to aggregate involuntary unemployment:

$$
\int_{0}^{c^{*}} u_{c} \mathrm{~d} H(c)=H\left(c^{*}\right)-\bar{m}
$$

Previous studies tend to impose restrictive assumptions on the shape of the rationing schedule $u_{c}$. Typically, they assume that rationing is either efficient or uniform (e.g., Lee and Saez, 2012; Palda, 2000). Rationing is efficient if all unemployed individuals have larger costs of work than all employed individuals. An efficient rationing schedule thus has $u_{c}=0$ for all $c \in[0, x]$ and $u_{c}=1$ for all $c \in\left(x, c^{*}\right]$, with $H(x)=\bar{m}$. Rationing is uniform if every worker faces the same probability of unemployment, such that $u_{c}=\bar{u}$ for all $c \in\left[0, c^{*}\right]$. However, there is little reason to suspect that either case is a reasonably accurate description of reality. Indeed, 
it is notoriously hard to empirically determine people's utility surplus of work, let alone how unemployment probabilities depend on this surplus (cf. Luttmer, 2007). For this reason, I remain largely agnostic about the exact shape of the rationing schedule $u_{c}$. The only assumption I impose is on changes to the rationing schedule in response to a marginal change in policy parameters. Specifically, I preclude the possibility that some people's unemployment probabilities go up when others' go down.

Assumption 1 If $\mathrm{d} u_{c}>0$ for some $c \in\left(0, c^{*}\right]$, then $\mathrm{d} u_{c} \geq 0$ for all $c \in\left(0, c^{*}\right]$.

Intuitively, an increase (decrease) in the aggregate unemployment rate leads to weakly higher (lower) unemployment probabilities for every individual who would like to work.

The task of the government is to collect taxes and pay out benefits, and finance some exogenous revenue requirement $r$. The government's net budget is given by:

$$
\mathcal{B} \equiv n_{L} t_{L}+n_{U} t_{U}-r
$$

This budget must be non-negative in equilibrium, so that any positive outlays on transfers and exogenous expenditures are offset by tax revenue. I assume, for now, that social preferences are utilitarian. Given linear utility functions, this implies that the government does not care about the distribution of income. Social welfare is therefore obtained by integrating over individuals' utility: ${ }^{4}$

(6) $\mathcal{W} \equiv \int_{0}^{c^{*}}\left(\left(1-u_{c}\right)\left(w_{L}-t_{L}-c\right)+u_{c}\left(-t_{U}\right)\right) \mathrm{d} H(c)+\int_{c^{*}}^{\bar{c}}\left(-t_{U}\right) \mathrm{d} H(c)$.

The first integral aggregates the utility of all individuals who notionally supply labor. The first term within the integral represents the utility of the employed, and the second term represents the utility of the involuntary unemployed. The second integral aggregates the utility of the voluntary unemployed. Notice that individual utility maximization (as implied by eq. (3)) ensures that social welfare is unaffected by any marginal change in $c^{*}$.

\footnotetext{
${ }^{4}$ I can ignore any firm profits since they are fixed by the ration.
} 


\section{$2.2 \quad$ Policy implications}

Now consider a reform that raises one unit of income from the employed, $\mathrm{d} t_{L}=1 / n_{L}$, and redistributes this by providing the unemployed with a higher transfer, $\mathrm{d} t_{U}=-1 / n_{U}$. Taking the derivative of eq. (3) and substituting for the reform gives $\mathrm{d} c^{*}=-\left(1 / n_{L}+1 / n_{U}\right)<0$. Higher labor taxes and unemployment benefits both cause workers to exit the labor market and become voluntarily unemployed. Thus, the critical level of the costs of work decreases in response to the reform. Furthermore, taking the derivative of eq. (4), and substituting for $\mathrm{d} c^{*}$ yields:

$$
\int_{0}^{c^{*}} \mathrm{~d} u_{c} \mathrm{~d} H(c)=-\left(1-u_{c^{*}}\right) h\left(c^{*}\right)\left(\frac{1}{n_{L}}+\frac{1}{n_{U}}\right) \leq 0 .
$$

As the government makes unemployment more attractive, workers with costs of work $c^{*}$ exit the labor market. As long as some of those workers were employed before the reform $\left(u_{c^{*}}<1\right)$, this creates work opportunities for the involuntary unemployed with lower costs of work. Eq. (7) indicates that, as a result of this, their unemployment probabilities decrease. Indeed, combined with Assumption 1, eq. (7) implies that the unemployment probability of every individual with $c \in\left[0, c^{*}\right)$ weakly decreases in response to the reform.

The social welfare effects of the reform readily follow. With $\lambda$ denoting the marginal social value of public revenue, the net social welfare effect of any reform is given by $\mathrm{d} \mathcal{W}+\lambda \mathrm{d} \mathcal{B}$. Taking derivatives of the government budget in eq. (5), it follows that $\mathrm{d} \mathcal{B}=0$. The mechanical revenue gains from higher labor taxes exactly cancel out against the mechanical revenue losses from higher unemployment benefits. Moreover, there is no behavioral effect on government revenue because, due to the ration, $n_{L}=\bar{m}$ and $n_{U}=1-\bar{m}$. Thus, labor rationing causes the conventional distortive effect of raising the participation tax to disappear. While the reform has no efficiency effects on the government budget, it does affect the efficiency of the ration itself as illustrated by the drop in unemployment probabilities. This can be seen by taking the derivative of the social welfare function in 
eq. (6):

$$
\mathrm{d} \mathcal{W}=-\int_{0}^{c^{*}}\left(c^{*}-c\right) \mathrm{d} u_{c} \mathrm{~d} H(c) \geq 0
$$

The inequality directly follows from the inequality in eq. (7) and Assumption 1 . The inequality holds strictly as long as involuntary unemployment rates among individuals with costs of work $c^{*}$ is lower than one: $u_{c^{*}}<1$. In that case, workers with costs of work $c^{*}$ decide to become voluntarily unemployed, leaving their jobs for individuals with costs of work $c \in\left[c, c^{*}\right)$. This leads to more efficient rationing as jobs are transferred from those with a low utility surplus of work to those with a high utility surplus of work. The welfare effects of this efficiency gain, as illustrated in eq. (8), consist of the difference $c^{*}-c$ for every individual who manages to find a job.

Eq. (8) implies that raising both taxes on the working and transfers to the unemployed is weakly welfare improving as long as there is rationing in the labor market. The policy implication is therefore to increase taxes and unemployment benefits up to the point at which all involuntary unemployment has been replaced by voluntary unemployment. In the special case of efficient rationing, such policy would leave social welfare unaffected: both pre-reform involuntary unemployment and post-reform voluntary unemployment are then concentrated on those individuals with the highest costs of work. But for any other rationing schedule, substituting voluntary unemployment for involuntary unemployment strictly improves welfare. It ensures that individuals with high costs of work give up their jobs to individuals with low costs of work.

It makes intuitive sense that this policy is optimal if marginal utilities of consumption are constant and social preferences utilitarian. With such individual and social preferences, government is merely concerned with efficiency. Since the market mechanism is not likely to generate an efficient allocation of jobs in the presence of rationing, it is optimal for government to correct this inefficiency with its tax instruments. As it turns out, the policy implication is independent of the assumption of utilitarian social preferences. Note that the policy reform involves a transfer of resources from the working population towards the unemployed, i.e., higher $t_{L}$, lower $t_{U}$. Besides the efficiency gain, this reform therefore leads to a distribu- 
tional gain for any government that values redistribution from individuals with high utility (or high income) towards individuals with low utility (or low income). Thus, the classical equity-efficiency trade-off of progressive taxation no longer holds in the presence of labor rationing. The findings from this stylized model are summarized in the following Proposition.

Proposition 1 Consider an economy with a single type of labor as the sole factor of production, in which labor supply exceeds demand. In such setting it is optimal for the government to increase both taxes for workers and benefits for the unemployed, such that workers with a low utility surplus of work voluntarily become unemployed, thereby creating jobs for unemployed individuals that derive more utility from working. This reform increases the efficiency of the labor ration, and improves equity by transferring resources from workers to the unemployed. Government optimally raises taxes and benefits to a point at which involuntary unemployment is entirely replaced by voluntary unemployment.

\subsection{Graphical representation and discussion of results}

The previous analysis points to a little recognized inefficiency related to involuntary unemployment, originating from heterogeneity of individuals' disutility of labor participation. Some of the employed are bound to have higher costs of work than some of the unemployed because there is no market mechanism that ensures otherwise. Thanks to the model's uncomplicated nature, this basic narrative of the paper can readily be illustrated by familiar graphical representation of the labor market. Figure 1 illustrates the additional dead-weight loss created by inefficient rationing in the absence of taxes and transfers. Panel a. shows the extreme case of perfectly efficient rationing in which the dead-weight loss equals the conventional red triangle IV. Producer surplus is given by the blue area I. Individuals that succeed in obtaining a job are the ones that have the highest utility surplus of work, represented by the leftmost part on the labor supply curve. Worker surplus is therefore given by the blue areas II and III.

The opposite extreme is illustrated in panel b. Only the people with the lowest positive utility surplus of working obtain a job, represented by the rightmost part of the labor supply curve as shown in the first graph. As 

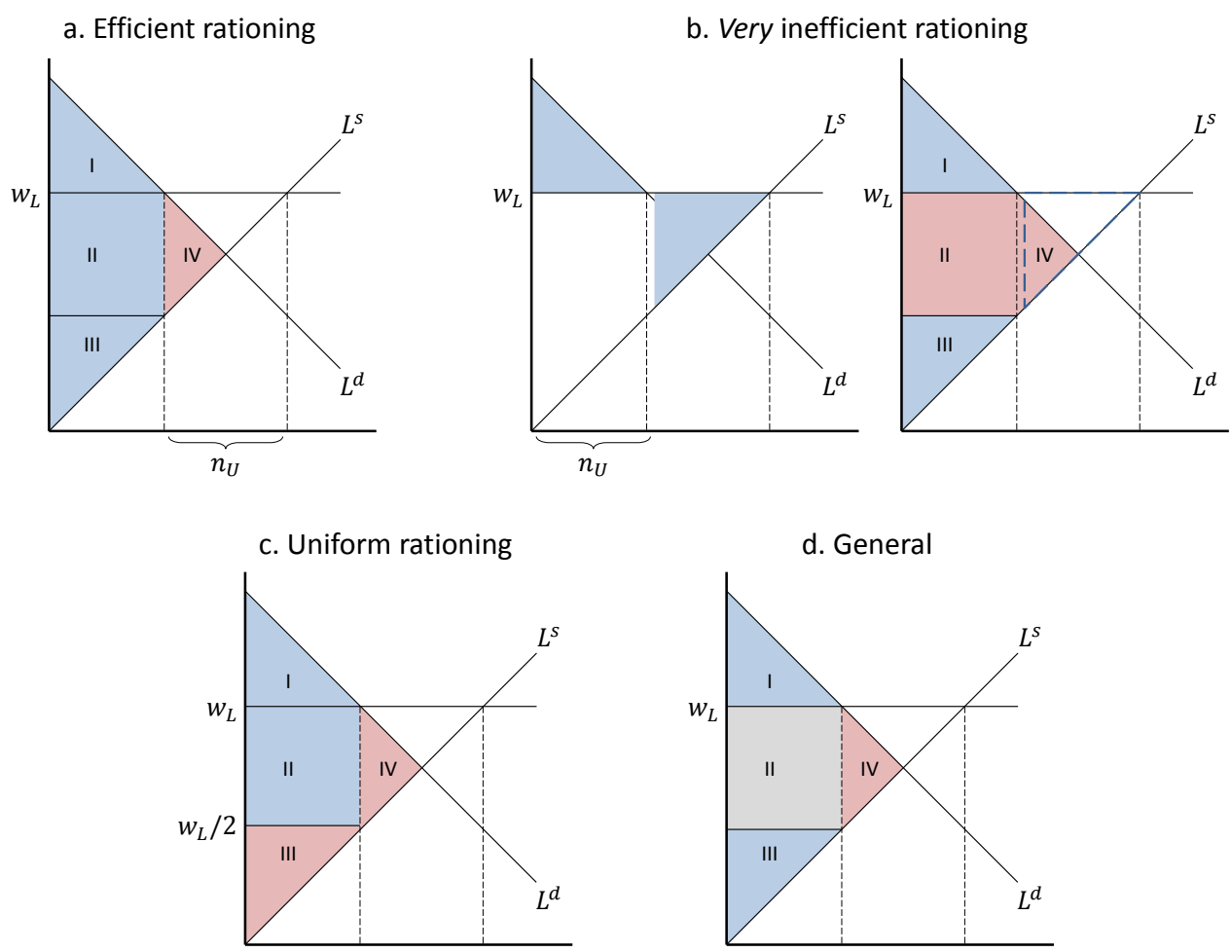

Figure 1: Deadweight loss for various rationing schedules

shown in the second graph, worker surplus now equals area III, generating an additional dead-weight loss, equal to area II, over and above the conventional dead-weight loss of area IV. As drawn in this figure, the additional dead-weight loss exceeds the conventional dead-weight loss.

The intermediate case of uniform rationing, in which every worker has an equal probability of unemployment, such that $u_{c}=\bar{u}$ for all $c \in\left[0, c^{*}\right]$, is illustrated in panel c. Given a linear supply schedule - which implies a uniform distribution of the costs of work - average costs of work now equals $w_{L} / 2$. I can therefore illustrate worker surplus by the blue rectangle II, which gives the number of workers multiplied by $w_{L} / 2$. The additional dead-weight loss in this case equals the red area III. As drawn in the figure, the additional dead-weight loss again exceeds the conventional dead-weight loss. Palda (2000) provides some calculations of the size of the two different dead-weight losses based on a simple calibration of the uniform-rationing case. He shows that area III exceeds area IV especially for low levels of rationing. This owes to the fact that the conventional dead-weight loss of 
a marginal increase in unemployment is zero in the absence of rationing, making it a second-order welfare loss. The additional dead-weight loss, due to inefficient rationing, of a marginal increase in unemployment is strictly positive in the absence of rationing and hence represents a first-order welfare loss.

Panel d. of Figure 1 summarizes the earlier panels for the case of an $a$ priori unknown rationing schedule. Area II gives the potential dead-weight loss of inefficient rationing. For any realistic rationing schedule in between the two extremes of efficient and very inefficient rationing, area II will be part worker surplus, part dead-weight loss.

The proposed policy reform increases taxes for the working population and transfers for the unemployed population as long as involuntary unemployment is prevalent. Both aspects of the policy reform shift the labor supply schedule to the left, and does so until it intersects the labor demand schedule and the wage floor at the same point. At that point, the policy reform effectively brings the economy back to panel a., in which case area II represents a surplus divided between the employed and the unemployed. ${ }^{5}$ Hence, the policy reform improves equity by transferring resources from workers to the unemployed, and improves efficiency by removing the inefficiency of the rationing schedule. The contrast with the standard analysis in public finance is striking. Without initial involuntary unemployment, the same reform would result in the same labor supply response. However, instead of generating an efficiency gain, this labor supply response would result in an efficiency loss, represented by the familiar dead-weight loss triangle of area IV. In the presence of involuntary unemployment, however, this dead-weight loss is already prevalent and lower labor supply improves, rather than worsens, efficiency.

Within the confinement of the model, Proposition 1 states that government optimally uses its tax instruments to remove any involuntary unemployment. Consequently, a binding minimum wage or other policies raising

\footnotetext{
${ }^{5}$ One might be led to believe that area II equals the tax revenue of the government and thus constitutes the utility surplus of the unemployed, such that workers' utility is measured solely by area III. However, the labor supply schedule shifts leftwards not only because of higher taxes, but also because of higher unemployment benefits. Thus, tax revenue is necessarily smaller than area III, and part of this area in fact constitutes workers' utility.
} 
wages above market-clearing levels are not optimal. My findings also shed new light on participation policy. The aims of such policy can be interpreted as increasing the critical level, $c^{*}$, and thus shifting the labor supply curve further to the right. My analysis shows that, if labor markets are rationed, it is optimal to decrease participation. In the best-case scenario of efficient rationing, higher participation leads to no welfare change at all. But in any other scenario, it leads to welfare losses due to more inefficient rationing. Hence, the wisdom of participation policy crucially depends on whether the relevant segment of the labor market is rationed or not. If it is, increasing participation will merely lead individuals with a low utility surplus of work to take over jobs of other individuals with a higher utility surplus of work. Taking a cyclical interpretation of my results, the presence of inefficient rationing suggests the optimality of anticyclical tax wedges on labor supply. After all, the 'normal' distortive effects of taxes and unemployment benefits are less relevant in an economic slump characterized by rigid wage floors and concurrent high involuntary unemployment. ${ }^{6}$

\section{Mixed rationing}

\subsection{Model}

\subsubsection{Firms}

In this section I assume there are two different types of labor - skilled and unskilled - that are imperfect substitutes in production. Wages for skilled workers are flexible and therefore free to equate demand and supply on the skilled segment of the labor market. Wages for unskilled workers, on the other hand, are fixed at a level above the market-clearing wage, which can be thought of as a consequence of minimum wage legislation, union wage setting, efficiency wages or some other form of institutionalized wage rigidity. ${ }^{7}$ As a result, unskilled labor demand will be insufficient to cover labor supply, causing involuntary unemployment among the unskilled.

\footnotetext{
${ }^{6}$ This cyclical interpretation echoes the results of Landais, Michaillat, and Saez (2013), who argue in favor of anticyclical unemployment benefits for similar reasons.

${ }^{7}$ In this section, I do not explicitly model the specific source of rationing, but instead simply assume it as exogenously given. I briefly return to this point in the next section, in which I consider a simple extension with a union-set wage floor.
} 
There is a representative, competitive, profit-maximizing firm that produces output, $Y$, by employing skilled and unskilled labor as inputs. I denote aggregate skilled labor as $n_{H}$ and unskilled labor as $n_{L}$. Because every worker supplies one unit of labor, $n_{H}$ and $n_{L}$ can be thought of as the number of skilled and unskilled workers. I normalize the price of output to unity and assume that production is a function of skilled and unskilled labor:

$$
Y=F\left(n_{H}, n_{L}\right), \quad F_{H}, F_{L}>0, \quad F_{H H}, F_{L L}<0, \quad F_{H L}>0 .
$$

Subscripts $H$ and $L$ of the production function denote partial derivatives with respect to $n_{H}$ and $n_{L}$. Marginal products of both types of labor are positive, and decreasing in own-type employment while increasing in other-type employment. I moreover assume that the production function is homogeneous of degree one and that both skilled and unskilled labor are essential factors of production: $F\left(n_{H}, 0\right)=F\left(0, n_{L}\right)=0$ and $\lim _{n_{j} \rightarrow 0} F_{j}=$ $\infty$ for both $j \in\{H, L\}$.

Firms demand labor, taking wages as given. The first-order conditions for profit maximization imply that the marginal productivities of labor equal the gross wage rates of each type of worker. Denoting skilled and unskilled wage rates by $w_{H}$ and $w_{L}$, I can write:

$$
\begin{gathered}
F_{H}\left(n_{H}, n_{L}\right)=F_{H}\left(\frac{n_{H}}{n_{L}}, 1\right)=w_{H}, \\
F_{L}\left(n_{H}, n_{L}\right)=F_{L}\left(\frac{n_{H}}{n_{L}}, 1\right)=w_{L}
\end{gathered}
$$

where the first equalities follow from degree-one homogeneity of the production function. I assume that skilled wages are higher than unskilled wages, $w_{H}>w_{L}$. Eq. (11) implies that a rigid wage floor, $w_{L}$, determines the relative factor intensity, $n_{H} / n_{L}$. Eq. (10) implies that this relative factor intensity in turn pegs down the skilled wage rate, $w_{H}$. That is, as long as unskilled workers are rationed, firms are willing to hire any amount of skilled workers at a fixed wage rate $w_{H}$. Any increase in skilled labor supply causes firms to expand both skilled and unskilled employment, leaving marginal productivities and wage rates unaffected. Thus, a binding wage 
floor for the unskilled fixes both skilled and unskilled wages, and ensures that unskilled employment can be written as a fixed proportion of skilled employment:

$$
n_{L}=\gamma n_{H},
$$

with $\gamma>0$ denoting some positive constant.

\subsubsection{Individuals}

I again assume there is a unit-mass continuum of individuals $\mathcal{I}$. Individuals are heterogeneous with respect to $c$, distributed according to $H(c)$, with density $h(c) \equiv H^{\prime}(c)$ and support $[0, \bar{c}]$. Individuals decide whether to supply labor as a skilled worker, notionally supply labor as an unskilled worker, or be voluntarily unemployed. Individual $i$ 's costs of unskilled work is denoted by $c^{i}$. I assume that skilled employment requires more effort and expenses than unskilled employment, and write individual $i$ 's costs of skilled work as $(1+\beta) c^{i}$ with $\beta>0$.

Government observes individual labor income. As a result, it can set income-specific (and thus skill-specific) taxes. Taxes for skilled workers, unskilled workers, and the unemployed are given by $t_{H}, t_{L}$, and $t_{U}$. Naturally, as the government is required to run a balanced budget, one or more of these taxes might be negative and thus represent a transfer. The utility functions of individual $i \in \mathcal{I}$ when skilled employed, unskilled employed, and unemployed are given by:

$$
\begin{aligned}
V_{H}^{i} & \equiv w_{H}-t_{H}-(1+\beta) c^{i}, \\
V_{L}^{i} & \equiv w_{L}-t_{L}-c^{i}, \\
V_{U}^{i} & \equiv-t_{U} .
\end{aligned}
$$

Preferences are chosen in such a way that individuals with low costs of work prefer to supply skilled labor, individuals with intermediate costs of work prefer to supply unskilled labor, and individuals with high costs of work prefer to be unemployed.

With unskilled labor rationing, some of the individuals who notionally supply unskilled labor do not manage to find a job. The unemployment 
probability for individuals with costs of work $c$ is given by $u_{c}$. The expected utility of an individual $i \in \mathcal{I}$ who notionally supplies unskilled labor is thus given by:

$$
E V_{L}^{i} \equiv\left(1-u_{c^{i}}\right) V_{L}^{i}+u_{c^{i}} V_{U}^{i}
$$

I again impose Assumption 1 on the rationing schedule and moreover assume that unemployment probabilities are continuous in $c$.

Assumption 2 The unemployment probability $u_{c}$ is continuous in costs of work $c$ for all $c$.

This technical assumption is imposed to ensure that there is always a level of $c$ for which an individual is indifferent between being skilled or unskilled. ${ }^{8}$

There are now (at least) two critical levels for the costs of work. One critical level, denoted $c_{s}^{*}$, separates the skilled from the unskilled; the other critical level, denoted $c_{u}^{*}>c_{s}^{*}$, separates the voluntary unemployed from the unskilled employed. This equilibrium is graphically illustrated in Figure 2. The upper critical level of the costs of work, $c_{u}^{*}$, is identical to the one in the previous section. It equates the utility of being unskilled employed with the utility of being unemployed, $V_{L}^{i}=V_{U}^{i}$ :

$$
c_{u}^{*}=w_{L}-t_{L}+t_{U}
$$

Individuals with costs of work above this critical level decide to be voluntarily unemployed; individuals with costs of work below this critical level choose to supply labor. The critical level, and thus unskilled labor supply, are decreasing in the unskilled income tax and the unemployment benefit as both increase the attractiveness of unemployment.

Individuals decide to be skilled or unskilled before knowing whether they are actually able to secure a job as an unskilled worker. They do know their probability of obtaining a job. The lower critical value, $c_{s}^{*}$, is therefore determined by equating skilled utility and expected unskilled

\footnotetext{
${ }^{8}$ As local continuity is sufficient for this to hold, Assumption 2 is more restrictive than necessary.
} 


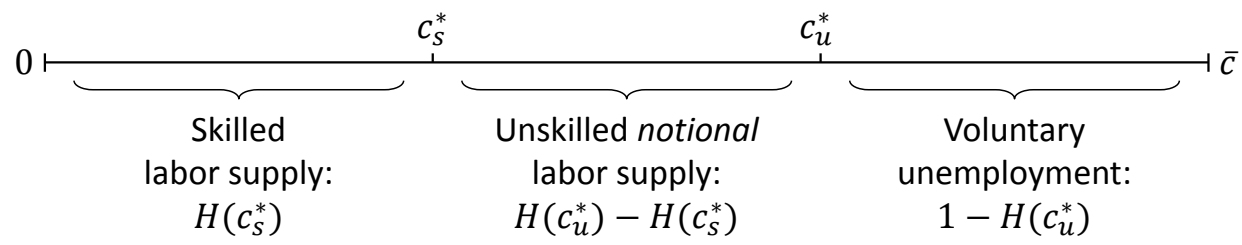

Figure 2: Graphical illustration of an equilibrium

utility: $V_{H}^{i}=E V_{L}^{i}$. Substituting for utility and rearranging yields:

$$
\beta c_{s}^{*}=\left(w_{H}-t_{H}\right)-\left(w_{L}-t_{L}\right)+u_{c_{s}^{*}}\left(c_{u}^{*}-c_{s}^{*}\right) .
$$

I assume that this critical level separating the skilled from the unskilled is unique so that $c_{u}^{*}$ and $c_{s}^{*}$ fully determine labor supply. ${ }^{9}$ The critical value, and thus skilled labor supply, are decreasing in the skilled income tax and increasing in the unskilled income tax. Moreover, if the individual with costs of work $c_{s}^{*}$ chooses unskilled employment, he faces unemployment with probability $u_{c_{s}^{*}}$. Relative to unskilled employment, such unemployment would reduce his utility by $c_{u}^{*}-c_{s}^{*}=w_{L}-t_{L}-c_{s}^{*}+t_{U}$. Thus, skilled labor supply is further increasing in $u_{c_{s}^{*}}$ and $c_{u}^{*}-c_{s}^{*}$ as both reduce the attractiveness of supplying unskilled labor.

\subsubsection{Labor market equilibrium}

As indicated in Figure 2, the model ensures that individuals with $c \in\left[0, c_{s}^{*}\right)$ supply skilled labor, individuals with $c \in\left[c_{s}^{*}, c_{u}^{*}\right]$ notionally supply unskilled labor, and individuals with $c \in\left(c_{u}^{*}, \bar{c}\right]$ choose to become voluntarily unemployed. Thus, skilled labor supply equals $H\left(c_{s}^{*}\right)$, unskilled notional labor supply equals $H\left(c_{u}^{*}\right)-H\left(c_{s}^{*}\right)$, and voluntary unemployment is given by $1-H\left(c_{u}^{*}\right)$. As the skilled segment of the labor market clears, skilled labor supply equals demand: $H\left(c_{s}^{*}\right)=n_{H}$. However, as the unskilled segment of the labor market is rationed, notional unskilled labor supply exceeds

\footnotetext{
${ }^{9}$ Depending on the rationing schedule $u_{c}$, it is theoretically possible that there are multiple levels of $c$ that equate skilled utility and expected unskilled utility. For example, one could imagine an interval for the costs of work in which $u_{c}$ is so high that those individuals strictly prefer skilled over unskilled labor supply, even though their costs of work is between $c_{s}^{*}$ and $c_{u}^{*}$. This interval would generate two more critical levels of $c$. While such a multitude of critical levels would make notation more cumbersome, it would not affect any of the conclusions and I therefore simply assume it away.
} 
unskilled labor demand: $H\left(c_{u}^{*}\right)-H\left(c_{s}^{*}\right)>n_{L}$. In equilibrium, aggregate unemployment is determined by the difference between supply and demand:

$$
\int_{c_{s}^{*}}^{c_{u}^{*}} u_{c} \mathrm{~d} H(c)=H\left(c_{u}^{*}\right)-(1+\gamma) H\left(c_{s}^{*}\right),
$$

where I applied eq. (12) to substitute for $n_{L}=\gamma n_{H}=\gamma H\left(c_{s}^{*}\right)$. I can now define equilibrium in the labor market as a set of values for $c_{s}^{*}, c_{u}^{*}$, and $\left\{u_{c}\right\}$, which satisfies individuals' and firms' optimizing behavior as described by eqs. (17), (18), and (19). Notice that, while eq. (19) pins down aggregate unemployment, equilibrium is consistent with a multitude of different rationing schedules that determine how aggregate unemployment translates into individual unemployment probabilities.

\subsubsection{Government}

The government's budget is given by total tax revenue net of the exogenous revenue requirement:

$$
\mathcal{B} \equiv n_{H} t_{H}+n_{L} t_{L}+n_{U} t_{U}-r
$$

As before, I assume that social preferences are utilitarian, such that social welfare can be written as a simple sum of individuals' utility:

$$
\mathcal{W} \equiv \int_{0}^{c_{s}^{*}} V_{H}^{i} \mathrm{~d} H(c)+\int_{c_{s}^{*}}^{c_{u}^{*}} E V_{L}^{i} \mathrm{~d} H(c)+\int_{c_{u}^{*}}^{\bar{c}} V_{U}^{i} \mathrm{~d} H(c)
$$

Notice that individual utility maximization ensures that marginal changes in $c_{s}^{*}$ and $c_{u}^{*}$ leave social welfare unaffected.

\subsection{Policy implications of mixed rationing}

How do the policy implications from Proposition 1 carry over to a setting with mixed rationing? To answer this, I once more consider a tax reform that raises one unit of tax revenue from unskilled workers and redistributes this towards the unemployed: $\mathrm{d} t_{L}=1 / n_{L}$ and $\mathrm{d} t_{U}=-1 / n_{U}$. The reform increases incentives for unskilled workers to become voluntarily unemployed. This can be seen by taking the derivative of eq. (17) and 
substituting for the reform: $\mathrm{d} c_{u}^{*}=-\left(1 / n_{L}+1 / n_{U}\right)<0$. The critical level $c_{u}^{*}$ declines and, therefore, voluntary unemployment increases due to the reform. Taking the derivative of eq. (19) yields the effect of the reform on involuntary unemployment:

$$
\int_{c_{s}^{*}}^{c_{u}^{*}} \mathrm{~d} u_{c} \mathrm{~d} H(c)=-\left(1-u_{c_{u}^{*}}\right) h\left(c_{u}^{*}\right)\left(\frac{1}{n_{L}}+\frac{1}{n_{U}}\right)-\left(1-u_{c_{s}^{*}}+\gamma\right) \mathrm{d} n_{H},
$$

where I substituted for $\mathrm{d} H\left(c_{s}^{*}\right)=\mathrm{d} n_{H}$.

Notice that the first right-hand side term of eq. (22) is identical to the change in involuntary unemployment in case of a single rationed labor type, as given by the right-hand side of eq. (7). Unskilled workers with costs of work $c_{u}^{*}$ decide to exit the labor market and leave their jobs for the involuntary unemployed who value them more. The second term in eq. (22) indicates that involuntary unemployment declines even further if the reform also raises incentives to supply skilled labor, such that $\mathrm{d} n_{H}>0$. Indeed, if individuals with costs of work $c_{s}^{*}$ decide to switch to skilled employment, a share $1-u_{c_{s}^{*}}$ of them leave behind their unskilled jobs, thereby reducing involuntary unemployment among the unskilled. Moreover, any unit increase in skilled labor supply causes firms to increase unskilled labor demand by $\gamma$, further reducing involuntary unemployment. Naturally, a decrease in skilled labor supply would have the opposite effect and raise involuntary unemployment.

Before considering how the reform affects skilled labor supply, it is useful to first discuss the reform's effects on the government budget and social welfare. Recall that the net social welfare effect of a reform is given by $\mathrm{d} \mathcal{W}+\lambda \mathrm{d} \mathcal{B}$. Taking the derivative of the government budget, given in eq. (20), and substituting for $n_{L}=\gamma n_{H}$ and $n_{U}=1-n_{H}-n_{L}$, as well as the reform, yields:

$$
\mathrm{d} \mathcal{B} \equiv\left(\left(t_{H}-t_{U}\right)+\gamma\left(t_{L}-t_{U}\right)\right) \mathrm{d} n_{H}
$$

The mechanical revenue gain of raising a unit of tax revenue from the unskilled exactly cancels out against the mechanical revenue loss of providing the unemployed with an additional unit of benefits. However, contrary to the case with a single type of labor, the policy reform might have a behav- 
ioral effect on tax revenue if it affects skilled labor supply. As discussed above, any increase in skilled labor supply not only yields more skilled workers but also raises unskilled employment. As long as taxes are progressive, such that $t_{H}, t_{L}>t_{U}$, both effects increase tax revenue.

Taking the derivative of the social welfare function in eq. (21), and substituting for the reform, yields:

$$
\mathrm{d} \mathcal{W} \equiv-\int_{c_{s}^{*}}^{c_{u}^{*}}\left(c_{u}^{*}-c\right) \mathrm{d} u_{c} \mathrm{~d} G(c),
$$

which is identical to eq. (8). If the policy reform reduces aggregate involuntary unemployment, then $\mathrm{d} u_{c} \leq 0$ for all $c \in\left(c_{s}^{*}, c_{u}^{*}\right)$ by virtue of Assumption 1. Any unemployed individual who finds a job earns additional income equal to $c_{u}^{*}=w_{L}-t_{L}+t_{U}$, but also incurs costs of work $c$. Thus, the right-hand side of eq. (24) exactly measures the social welfare gain associated with reducing the inefficiency of the ration.

Aggregating the social welfare and budgetary effects of the reform yields the following net social welfare effect of raising both the unemployment benefit and the tax on rationed labor:

$$
\mathrm{d} \mathcal{W}+\lambda \mathrm{d} \mathcal{B}=-\int_{c_{s}^{*}}^{c_{u}^{*}}\left(c_{u}^{*}-c\right) \mathrm{d} u_{c} \mathrm{~d} G(c)+\lambda\left(\left(t_{H}-t_{U}\right)+\gamma\left(t_{L}-t_{U}\right)\right) \mathrm{d} n_{H}
$$

Taken together, eqs. (22) and (25) imply that a sufficient condition for the policy reform to have a net positive effect on social welfare is that it increases skilled labor supply. In that case, the policy reform not only reduces the inefficiency of the ration, but also increases tax revenue (as long as taxes are progressive). To determine under which condition the reform indeed increases skilled labor supply, recall that $\mathrm{d} n_{H}>0$ if and only if $\mathrm{d} c_{s}^{*}>0$. Taking the derivative of eq. (18) and substituting for the reform yields:

$$
\left(\beta+u_{c_{s}^{*}}\right) \mathrm{d} c_{s}^{*}=\left(1-u_{c_{s}^{*}}\right) \frac{1}{n_{L}}-u_{c_{s}^{*}}\left(\frac{1}{n_{U}}\right)+\left(c_{u}^{*}-c_{s}^{*}\right) \mathrm{d} u_{c_{s}^{*}} .
$$

Whether $\mathrm{d} c_{s}^{*}$ is indeed positive depends on three terms, reflecting the reform's effects on the incentives to supply skilled labor for an individual with costs of work $c_{s}^{*}$. First of all, an increase in the unskilled income tax makes 
it more attractive to become skilled. This is indicated by the first term on the right-hand-side of eq. (26). However, as long as individuals with costs of work $c_{s}^{*}$ face some positive probability of unemployment, the increase in unemployment benefits reduce incentives to become skilled (second term). Finally, if the policy reform reduces the unemployment probability for individuals with costs of work $c_{s}^{*}$, it raises their expected utility of being unskilled and therefore reduces incentives to become skilled (third term).

Whether or not the reform leads to more skilled labor supply crucially depends on the rationing schedule; more specifically, it depends on the unemployment probability of individuals at the skill margin, i.e., on $u_{c_{s}^{*}}$. If this unemployment probability is relatively large, an increase in unemployment benefits makes unskilled labor supply more attractive. A relatively large reform-induced reduction in this unemployment probability further enhances the attractiveness of unskilled labor supply. Indeed, a sufficient condition for skilled labor supply to increase in response to the policy reform is that the unemployment probability at the skill margin is nil: $u_{c_{s}^{*}}=0$. In that case, the policy reform only affects the skill decision of individuals with costs of work $c_{s}^{*}$ by increasing the tax rate on unskilled labor, thereby stimulating skilled labor supply. I summarize these main findings in the following Proposition.

Proposition 2 Consider an economy with skilled and unskilled labor in which unskilled labor is rationed. A policy reform that increases taxes for the unskilled and benefits for the unemployed improves equity by redistributing from the employed to the unemployed. It also unambiguously improves efficiency if the reform leaves skilled labor supply unaffected, or, in case of progressive taxes, if the reform increases skilled labor supply. The reform in that case reduces the inefficiency of the ration and raises tax revenue through increased skilled and unskilled employment. A sufficient condition for the reform to lead to more skilled labor supply is a negligible unemployment probability for individuals at the skill margin.

\subsection{Discussion}

In Proposition 1, I concluded that labor rationing causes the conventional trade-off between equity and efficiency to break down in the case of a sin- 
gle labor type. In the case of two types of labor, this section shows that a version of the equity-efficiency trade-off might resurface when the unskilled labor type is rationed while the skilled labor type is not. Raising taxes on the rationed labor type, as well as unemployment benefits, still improves equity but could either enhance or diminish efficiency. It enhances efficiency by encouraging unskilled workers with high costs of work to exit the labor market, thereby reducing the inefficiency of the ration. The increased tax on the unskilled moreover encourages some of them to supply skilled labor instead, further enhancing efficiency. However, the increase in the unemployment benefits, as well as the reduction in involuntary unemployment, might make unskilled labor supply more attractive to skilled workers. This would diminish efficiency by reducing both skilled and unskilled employment. If the positive effect on skilled labor supply outweighs the negative effect, raising unskilled taxes and unemployment benefits improves both equity and efficiency. If the negative effect on skilled labor supply is dominant, the reform improves equity only at the costs of reduced efficiency. ${ }^{10}$

In interpreting Proposition 2, it is helpful to distinguish between the short run and the long run (cf. Lee and Saez, 2012). It is conceivable that skill formation is relatively inelastic with respect to any short-run changes in the labor market, such that $\mathrm{d} n_{H} \approx 0$. Proposition 2 then implies that the equity-efficiency trade-off breaks down when the unskilled are faced with short-run rationing. Indeed, from eq. (25) we know that raising taxes on (unskilled) labor and unemployment benefits is in that case unambiguously desirable. In the longer run, individuals are more likely to take into account the conditions on the unskilled labor market when making decisions on skill formation. Indeed, it is found that a lower rate of unskilled unemployment discourages school enrollment and encourages dropping out of high school (e.g., Card and Lemieux, 2001; Clark, 2011). However, the same studies also typically find that lower remuneration for unskilled work encourages schooling. To the best of my knowledge, little is known about the net effect on schooling of reducing unskilled rationing through higher unemployment benefits and taxes on the unskilled - as I suggest in this paper.

\footnotetext{
${ }^{10}$ This is similar to the results of Gerritsen and Jacobs (2015), who find that a minimum wage can only be part of optimal policy if the resulting involuntary unemployment leads to sufficiently more skilled labor supply.
} 
Proposition 2 also underlines the crucial importance of the rationing schedule, $u_{c}$. On the one hand, the more inefficient is the rationing schedule, the higher are the efficiency gains from reducing rationing. This is evident from the first right-hand side term in equation (25). On the other hand, these efficiency gains are lower if the rationing schedule concentrates much of the involuntary unemployment on individuals that are relatively indifferent between skilled and unskilled work. If $u_{c_{s}^{*}}$ is high, reducing rationing by raising unskilled taxes and unemployment benefits is likely to lead to a reduction in skilled labor supply, as evident from eq. (26). Provided that taxes are set progressively, such a reduction would lead to a decline in tax revenue and therefore come with an efficiency loss. ${ }^{11}$

Indeed, Proposition 2 states that raising unskilled taxes and unemployment benefits unambiguously improves equity and efficiency if rationing does not affect the individuals that are indifferent between skilled and unskilled employment, such that $u_{c_{s}^{*}}=0$. Unfortunately, as mentioned above, very little is known about the exact shape of the rationing schedule. It nevertheless appears intuitively plausible that skilled workers are not rationed when they decide to switch to unskilled employment. In the words of Lee and Saez (2012), "it may be realistic that employers could preferentially hire the most qualified workers even for minimum wage jobs" (footnote 15, p.744). This effectively implies that $u_{c_{s}^{*}}=0$ and, according to Proposition 2 , that raising unskilled taxes and unemployment benefits is unambiguously desirable when faced with unskilled rationing.

\section{Further extensions}

\subsection{Employer-paid vs employee-paid taxes}

I have focussed exclusively on taxes that are directly paid by employees. It is conventional public-finance wisdom that it does not matter for the economic incidence of the income tax whether it is statutorily levied on employers or employees. Naively applying this incidence-equivalence principle

\footnotetext{
${ }^{11}$ This is related to the findings by Lee and Saez (2012) who argue that a minimum wage might be optimal if the resulting involuntary unemployment is concentrated on the unskilled who are relatively indifferent between either unskilled employment and unemployment or unskilled employment and skilled employment.
} 
suggests that the conclusion from previous sections - raising the employeepaid income tax on rationed labor might improve both equity and efficiency - should also hold for the employer-paid income tax. But in conventional models of the labor market, incidence equivalence holds because wages are assumed to be flexible. Higher employee-paid taxes reduce labor supply, thereby increasing wages; higher employer-paid taxes reduce labor demand, thereby reducing wages. In the end, the economic incidence of the tax increase is shared between employees and employers in the same way for both taxes. But as rationed labor markets are characterized by rigid wages, wages do not adjust to taxes and incidence equivalence no longer holds.

This can be shown formally by expanding the model of Section 3 with an employer-paid tax on unskilled labor, $\tau_{L}$, and compare the comparative statics of changes in $t_{L}$ and $\tau_{L}$. The firm's first-order condition for unskilled labor demand is now given by:

$$
F_{L}\left(n_{H}, n_{L}\right)=F_{L}\left(\frac{n_{H}}{n_{L}}, 1\right)=w_{L}+\tau_{L}
$$

I consider the effects of changes in $t_{L}$ and $\tau_{L}$, holding all other policy parameters constant. ${ }^{12}$ As there are no profits, all incidence of either tax falls exclusively on skilled and unskilled workers. Solving for the total derivatives of unskilled and skilled net income yields the following two equations:

$$
\begin{aligned}
\mathrm{d}\left(w_{L}-t_{L}\right) & =-\mathrm{d} t_{L}, \\
\mathrm{~d}\left(w_{H}-t_{H}\right) & =-\left(\frac{n_{L}}{n_{H}}\right) \mathrm{d} \tau_{L} .
\end{aligned}
$$

The first equation follows directly from the assumption of a rigid unskilled wage rate. The second equation is obtained by combining the derivatives of eqs. (10) and (27) and substituting for $n_{H} F_{H H}=-n_{L} F_{H L}$, which follows from linear homogeneity of the production function.

Eq. (28) indicates that all the incidence of the employee-paid tax falls on unskilled labor. Net income for an unskilled worker falls one-to-one

\footnotetext{
${ }^{12}$ Note that if government can separately set both employer-paid and employee-paid taxes, the rigid wage rate becomes irrelevant. Government could then effectively determine both employees' net wages and employers' labor costs, which is equivalent to setting a minimum wage along with an employee-paid income tax.
} 
with an increase in the employee-paid tax. But none of the incidence of the employer-paid tax falls on unskilled labor. Instead, eq. (29) shows that all the incidence of the employer-paid tax falls on skilled workers. To see this, note that the mechanical revenue gains from the employer-paid tax is given by $n_{L} \mathrm{~d} \tau_{L}$, which equals the total mechanical income loss of skilled workers, given by $-n_{H} \mathrm{~d}\left(w_{H}-t_{H}\right)$. Skilled workers' net income thus falls one-to-one with an increase in the employer-paid tax on unskilled income. Intuitively, the increase in employer-paid taxes reduces unskilled labor demand. As a result, unskilled employment declines, as does the marginal productivity of skilled labor. ${ }^{13}$

The difference between the two taxes is even more dramatic when considering their impact on involuntary unemployment. For simplicity, assume that skilled labor supply is inelastic, so that $\mathrm{d} n_{H}=\mathrm{d} c_{u}^{*}=0$. Substituting $n_{L}=\int_{c_{s}^{*}}^{c_{u}^{*}}\left(1-u_{c}\right) \mathrm{d} H(c)$ into eq. (27) and taking the total derivative, I obtain the following equation for the change in involuntary unemployment:

$$
\int_{c_{s}^{*}}^{c_{u}^{*}} \mathrm{~d} u_{c} \mathrm{~d} H(c)=-\left(1-u_{c_{u}^{*}}\right) h\left(c_{u}^{*}\right) \mathrm{d} t_{L}+\frac{1}{-F_{L L}} \mathrm{~d} \tau_{L},
$$

where I substituted for $\mathrm{d} c_{u}^{*}=-\mathrm{d} t_{L}$ from eq. (17). The first right-hand side term mirrors earlier findings. It indicates that a higher employee-paid tax on the unskilled reduces rationed labor supply, thereby leading to less involuntary unemployment. The second term is new. It indicates that a higher employer-paid tax reduces rationed labor demand, thereby leading to more involuntary unemployment. Thus, an employee-paid tax reduces labor supply whereas an employer-paid tax reduces labor demand. When flexible wages equate supply and demand, there is no difference between reducing demand or supply and the two taxes are equivalent. But in a rationed labor market, labor supply exceeds labor demand and involuntary unemployment is given by the difference. As a result, employee-paid taxes on unskilled labor alleviate labor rationing, while employer-paid taxes worsen it.

\footnotetext{
${ }^{13}$ Lehmann, Marical, and Rioux (2013) empirically document a difference between the effects of employer-paid and employee-paid taxes on individuals' gross income in France, in line with the existence of rigid wages.
} 


\subsection{Endogenous union-set wages}

So far, I assumed that involuntary unemployment was the result of an exogenous wage floor which exceeds the market-clearing wage. This explanation might have some merit, especially when considering unemployment over a relatively short time horizon. However, one could plausibly argue that some wage floors are endogenously determined by specific agents such as a trade union. If such agent cares about workers' net wages, which is presumably the reason why it sets a wage floor, a policy reform that increases unskilled labor taxes might induce it to increase the wage floor. As a result, the policy reform might reduce rationed labor demand as well as rationed labor supply, leading to an erosion of the tax base and causing the equity-efficiency trade-off to resurface. I show below that a higher level of labor taxes is indeed likely to raise wage demands of a union that cares about both net wages and employment. However, if government commits to raising taxes in response to an increase of involuntary unemployment, it directly incentivizes the union to moderate its wage demands. As the focus of the paper is on rigid wage floors, I only illustrate this findings in a highly reduced-form manner and leave a fuller treatment of optimal taxation with unions and inefficient rationing for future research. ${ }^{14}$

I return to the model of Section 3, but now assume that unskilled wages are set by a labor union. As is commonly observed (e.g., Booth, 1995), I assume that the goal function of the union depends positively on (unskilled) net wages and employment, according to:

$$
\begin{array}{r}
\Pi \equiv \Pi\left(w_{L}-t_{L}, n_{L}\right), \quad \Pi_{w_{L}-t_{L}}, \Pi_{n_{L}}, \Pi_{w_{L}-t_{L}, n_{L}}>0, \\
\Pi_{w_{L}-t_{L}, w_{L}-t_{L}} \Pi_{n_{L}, n_{L}}<0,
\end{array}
$$

where subscripts denote partial derivatives with respect to net wages and employment. The union maximizes this function, subject to firm behavior which determines employment, $n_{L}$, and government behavior which determines the tax rate, $t_{L}$. For simplicity, I assume that the production function implies a constant elasticity of labor demand which equals $\varepsilon \equiv-\frac{\mathrm{d} n_{L}}{\mathrm{~d} w_{L}} \frac{w_{L}}{n_{L}}>0$. First suppose that $t_{L}$ is exogenously set by the government and thus in-

\footnotetext{
${ }^{14}$ See, for example, Hummel and Jacobs (2016) for a recent treatment of the subject.
} 
dependent of the level of unemployment. The labor union then sets wages according to:

$$
\frac{\Pi_{w_{L}-t_{L}}}{\prod_{n_{L}}} \frac{w_{L}}{n_{L}}=\varepsilon
$$

As long as the left-hand side of eq. (32) is larger than $\varepsilon$, the union raises wage demands as the marginal gains from higher net wages outweigh the marginal employment costs. For equation (32) to represent an equilibrium wage rate, I need to assume that the left-hand side is declining with the gross wage rate. This holds true if the complementarity between net wages and employment in the union's goal function is sufficiently strong. ${ }^{15}$

Equation (32) implies that gross wage demands increase in response to an income tax increase. The direct effect of a tax increase is to raise the union's marginal rate of substitution of net wages for employment, $\Pi_{w-t_{L}} / \Pi_{n_{L}}$, raising the left-hand side of equation (32) above $\varepsilon$. Consequently, the union raises the gross wage rate until equilibrium is restored. It would be wrong, however, to interpret this as discrediting the results of Sections 2 and 3. After all, those sections argued that income taxation should not be set exogenously but be determined by and depend positively on unemployment. That is, income taxation should be endogenous with respect to the union's decisions that affect the degree of unemployment. Losing the assumption of an exogenously set labor tax, the union-set equilibrium wage rate can now be seen to equal:

$$
\frac{\Pi_{w_{L}-t_{L}}}{\prod_{n_{L}}} \frac{w_{L}}{n_{L}}\left(1-\frac{\mathrm{d} t_{L}}{\mathrm{~d} w_{L}}\right)=\varepsilon
$$

Notice that the only difference with equation (32) is the additional term $\left(1-\mathrm{d} t_{L} / \mathrm{d} w_{L}\right)$ on the left-hand side. This term implies that government can directly influence the union's marginal gains of increasing its wage demands. Regardless of the level of taxation, if taxes depend positively on unemployment, $\mathrm{d} t_{L} / \mathrm{d} w_{L}>0$, the union's gains from raising wages is

\footnotetext{
${ }^{15}$ Hence, the second-order condition requires that $\frac{\Pi_{w_{L}-t_{L}}}{\Pi_{n_{L}}} \frac{w_{L}}{n_{L}}$ is decreasing in the wage rate $w_{L}$. As long as labor taxes are nonnegative, a sufficient condition for this is that $\frac{\Pi_{w_{L}-t_{L}}}{\Pi_{n_{L}}} \frac{w_{L}-t_{L}}{n_{L}}$ is decreasing in $w_{L}$, which implies that the union's elasticity of substitution of net wages for employment at the equilibrium is smaller than one.
} 
diminished since only part of a gross wage increase is translated into a net wage increase. Thus, in the presence of an endogenously set wage floor, government can directly influence this wage floor by making taxes dependent on unemployment. According to the logic of previous sections, government should make taxes depend positively on unemployment in order to reduce inefficient rationing. ${ }^{16}$

\section{Concluding remarks}

My analysis of rationed labor markets stresses an inefficiency which has not received much attention. With too little jobs for too many potential workers, the market mechanism does not necessarily allocate jobs to the people that derive most utility from the job. Because of this inefficiency, government might find it optimal to tax the individuals who derive least utility from working out of the labor market, while using the additional revenue to increase unemployment benefits. Propositions 1 and 2 establish that, under fixed skill formation, such tax reform improves efficiency as well as equity. The efficiency improvement, originating from the reallocation of jobs, is in stark contrast to public-finance orthodoxy which predicts a trade-off between equity and efficiency as lower labor supply erodes the tax base. In rationed labor markets this orthodoxy is invalid as the tax base is determined by labor demand rather than labor supply.

I argue that the assumption of fixed skill formation might be appropriate for the short run, but less so for the long run. Proposition 2 establishes that the reform enhances both equity and efficiency if it leads to higher skilled labor supply. This holds true if rationing is not concentrated on the unskilled workers that are relatively indifferent between skilled and unskilled work. I moreover show that the incidence of employer taxes and employee taxes are very different in the presence of labor rationing - again in

\footnotetext{
${ }^{16}$ Even if taxes are invariant to unemployment, a similar result would obtain if I allow government to set marginal tax rates as well as income-specific lump-sum taxes. A positive marginal income tax discourages trade unions from raising wage demands as higher wages lead to higher tax burdens. See also earlier literature that discusses how the progressivity of the tax system affects unions' wage-setting behavior (e.g., Hersoug, 1984; Lockwood and Manning, 1993; Bovenberg and van der Ploeg, 1994; Koskelen and Vilmunen, 1996; Fuest and Huber, 1997, 2000; Sørensen, 1999; Aronsson and Sjögren, 2004).
} 
stark contrast to public-finance orthodoxy. Higher employee taxes improve efficiency by reducing involuntary unemployment, whereas higher employer taxes increase involuntary unemployment. Finally, I show that the policy implication - government should raise taxes and unemployment benefits in response to higher unemployment - carries over to a simple model where the wage floor is endogenously determined by a labor union.

These results have implications for government policies beyond optimal taxation. Naturally, if rationing is optimally removed by appropriately setting taxes, government-imposed rationing arising from a binding minimum wage cannot be optimal. Government can use the same information required to enforce a minimum wage to set taxes and transfers in such a way that the minimum wage is no longer binding, thereby removing the inefficiency of rationing while redistributing income from rich to poor. Policies that encourage participation are also ill-advised if the relevant segment of the labor market is rationed. Normally, participation policies are justified by pointing out that a positive income tax wedge distorts the participation decision. Encouraging participation might lead to efficiency gains as it partially offsets this tax distortion. But if the relevant labor market segment is rationed, this argument has no bite. Instead, higher participation leads to an efficiency loss as more individuals with relatively high costs of work start competing with others for a limited amount of jobs. ${ }^{17}$ Hence, in determining the wisdom of participation policies it is crucial to understand whether the additional labor supply can add to aggregate employment or whether it merely increases unemployment among workers who derive more utility from working.

The material point of this paper is that the presence of involuntary unemployment drastically alters the efficiency properties of taxation. Discouraging labor supply, which would be inefficient in the case of full employment, could be efficient in the presence of involuntary unemployment. This can also be given a cyclical interpretation. During times of high unemployment - for example due to a negative productivity shock combined with downward wage rigidity - the welfare costs of labor income taxation

\footnotetext{
${ }^{17}$ Indeed, Crépon et al. (2013) provide empirical evidence that certain participation policies - in this case job placement assistance - improve some people's employment chances, but at the cost of lower employment chances for others. They find that this displacement effect is particularly strong in weak labor markets.
} 
and unemployment benefits are relatively low. This suggests the optimality of both anticyclical labor taxation and anticylical unemployment benefits.

\section{References}

Allen, Stephen P. 1987. "Taxes, redistribution, and the minimum wage: A theoretical analysis." Quarterly Journal of Economics 102 (3):477-489.

Aronsson, Thomas and Tomas Sjögren. 2004. "Is the optimal labor income tax progressive in a unionized economy?" The Scandinavian Journal of Economics 106 (4):661-675.

Boadway, Robin and Katherine Cuff. 2001. "A minimum wage can be welfare-improving and employment-enhancing." European Economic Review 45 (3):553-576.

Booth, Alison L. 1995. The Economics Of The Trade Union. Cambridge: Cambridge University Press.

Bovenberg, A. Lans and Frederick van der Ploeg. 1994. "Effects of the tax and benefit system on wage formation and unemployment." Mimeo.

Bulow, Jeremy and Paul Klemperer. 2012. "Regulated prices, rent seeking, and consumer surplus." Journal of Political Economy 120 (1):160-186.

Card, David and Thomas Lemieux. 2001. "Dropout and enrollment trends in the postwar period: What went wrong in the 1970s?" In Risky behavior among youths: An economic analysis, edited by Jonathan Gruber. University of Chicago Press, 439-482.

Chetty, Raj. 2009. "Is the taxable income elasticity sufficient to calculate deadweight loss? The implications of evasion and avoidance." American Economic Journal: Economic Policy 1 (2):31-52.

Clark, Damon. 2011. "Do Recessions Keep Students in School? The Impact of Youth Unemployment on Enrolment in Post-compulsory Education in England." Economica 78 (311):523-545. 
Crépon, Bruno, Esther Duflo, Marc Gurgand, Marc Rathelot, and Philippe Zamora. 2013. "Do labor market policies have displacement effects? Evidence from a clustered randomized experiment." The Quarterly Journal of Economics 128 (2):531-580.

Davis, Lucas W. and Lutz Kilian. 2011. "The allocative cost of price ceilings in the U.S. residential market for natural gas." Journal of Political Economy 119 (2):212-241.

Deacon, Robert T. and Jon Sonstelie. 1989. "The welfare costs of rationing by waiting." Economic Inquiry 27 (2):179-196.

Feldstein, Martin. 1999. "Tax avoidance and the deadweight loss of the income tax." The Review of Economics and Statistics 81 (4):674-680.

Frech, Harry E. and William C. Lee. 1987. "The welfare cost of rationingby-queuing across markets: Theory and estimates from the U.S. gasoline crises." The Quarterly Journal of Economics 102 (1):97-108.

Fuest, Clemens and Bernd Huber. 1997. "Wage bargaining, labor-tax progression, and welfare." Journal of Economics 66 (2):127-150.

. 2000. "Is tax progression really good for employment? A model with endogenous hours of work." Labour Economics 7:79-93.

Gerritsen, Aart and Bas Jacobs. 2015. "Is a minimum wage an appropriate instrument for redistribution?" Mimeo.

Glaeser, Edward L. and Erzo F.P. Luttmer. 2003. "The misallocation of housing under rent control." The American Economic Review 93 (4):1027-1046.

Guesnerie, Roger and Kevin Roberts. 1987. "Minimum wage legislation as a second best policy." European Economic Review 31 (1-2):490-498.

Hersoug, Thor. 1984. "Union wage responses to tax changes." Oxford Economic Papers 36:37-51.

Hummel, Albert Jan and Bas Jacobs. 2016. "Optimal income taxation in unionized labor markets." Mimeo. 
Koskelen, Erkki and Jouko Vilmunen. 1996. "Tax progression is good for employment in popular models of trade union behaviour." Labour Economics 3:65-80.

Kroft, Kory, Kavan Kucko, Etienne Lehmann, and Johannes Schmieder. 2015. "Optimal income taxation with unemployment and wage responses: A sufficient statistics approach." Mimeo.

Landais, Camille, Pascal Michaillat, and Emmanuel Saez. 2013. "Optimal unemployment insurance over the business cycle." National Bureau of Economic Research Working Paper No. 16526.

Lee, David and Emmanuel Saez. 2012. "Optimal minimum wage policy in competitive labor markets." Journal of Public Economics 96 (9-10):739749 .

Lehmann, Etienne, François Marical, and Laurence Rioux. 2013. "Labor income responds differently to income-tax and payroll-tax reforms." Journal of Public Economics 99 (4):66-84.

Lichter, Andreas, Andreas Peichl, and Sebastian Siegloch. 2015. "The ownwage elasticity of labor demand: A meta-regression analysis." European Economic Review 80:94-119.

Lockwood, Ben and Alan Manning. 1993. "Wage setting and the tax system: Theory and evidence for the United Kingdom." Journal of Public Economics 52:1-29.

Lott, John R. 1990. "Nontransferable rents and an unrecognized social cost of minimum wage laws." Journal of Labor Research 11 (4):453-460.

Luttmer, Erzo F.P. 2007. "Does the Minimum Wage Cause Inefficient Rationing?" BE Journal of Economic Analysis \& Policy 7 (1). (Contributions, Article 49).

Marceau, Nicolas and Robin Boadway. 1994. "Minimum wage legislation and unemployment insurance as instruments for redistribution." The Scandinavian Journal of Economics 96 (1):67-81. 
Neumark, David and William Wascher. 2006. "Minimum wages and employment: A review of evidence from the new minimum wage research." National Bureau of Economic Research Working Paper No. 12663.

Palda, Filip. 2000. "Some deadweight losses from the minimum wage: The cases of full and partial compliance." Labour Economics 7 (6):751-783.

Saez, Emmanuel, Joel Slemrod, and Seth H Giertz. 2012. "The elasticity of taxable income with respect to marginal tax rates: A critical review." Journal of Economic Literature 50 (1):3-50.

Schmitt, John. 2013. "Why does the minimum wage have no discernible effect on employment?" Center For Economic And Policy Research.

Sørensen, Peter Birch. 1999. "Optimal tax progressivity in imperfect labour markets." Labour Economics 6:435-452.

Tobin, James. 1952. "A Survey of the Theory of Rationing." Econometrica $20(4): 521-553$. 